
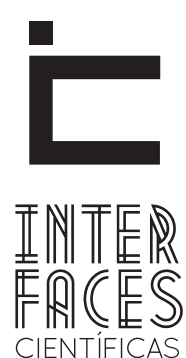

EDUCAÇÃO

ISSN IMPRESSO 2316-333X

E-ISSN 2316-3828

DOI-10.17564/2316-3828.2017v5n3p65-74

\title{
PROCESSO ENSINO-APRENDIZAGEM E O PARADIGMA CONSTRUTIVISTA
}

\author{
TEACHING-LEARNING PROCESS AND THE CONSTRUTIVIST PARADIGM \\ PROCEDIMIENTO ENSEÑANZA-APRENDIZAJE Y PARADIGMA CONSTRUTIVISTA
}

\section{RESUMO}

Esse ensaio teve como objetivo lançar reflexões acerca do processo ensino-aprendizagem à luz do paradigma construtivista, definindo-se como escopo a expectativa de sua repercussão sobre a prática pedagógica. Qualitativa, essa pesquisa enquadra-se como bibliográfica, em razão das características do campo, a produção bibliográfica sobre o tema, e a natureza da comunicação científica. A análise empreendida indica consenso e convergência em direção ao reconhecimento do valor pedagógico do referencial explicativo, inobstante se admita restrições e desafios de aplicação.

\section{PALAVRAS-CHAVE}

Construtivismo. Ensino-aprendizagem. Pedagogia. 


\section{ABSTRACT}

This paper objectified reflect about teaching and learning process using the constructivist paradigm, defining scope as to their expected impact on the pedagogical practice. Qualitative, this research fits as literature, due to the characteristics of the field, the literature on the theme, and the nature of scientific communication. The results indicates consensus and convergence towards the recognition of the ed-

\section{RESUMEN}

Este ensayo tuvo como objetivo lanzar reflexiones sobre el proceso de enseñanza-aprendizaje a la luz del paradigma constructivista, definiendo el alcance en cuanto a su impacto esperado en la práctica pedagógica. Cualitativa, esta investigación se ajusta como bibliográfica, debido a las características del terreno, la literatura acerca del tema y la naturaleza de la comunicación científica. El análisis realizado indica el consenso y la convergencia hacia el reconocimiento ucational value of explanatory reference, regardless of whether it is accepted restrictions and application challenges.

\section{KEYWORDS}

Constructivism. Teaching - learning. Pedagogy. del valor educativo de referencia explicativa, independientemente si se acepta restricciones y retos de aplicación.

\section{PALABRAS CLAVE}

Constructivismo. Enseñanza - aprendizaje.

Pedagogía. 


\section{INTRODUÇ̄̃̃O}

A Educação ocupa função primordial na vida do indivíduo, tendo em vista seu papel norteador na formação e emancipação da consciência humana (LÓPEZ, 1994). Essa condição responsabiliza o professor, social e moralmente, no processo de elaboração do conhecimento, na mediação entre sujeito e realidades, interpretação e articulação dos signos culturais, especialmente, na religação e conexão de saberes, ações genuinamente interdisciplinares.

A clássica educação disciplinar, desconectada da realidade e de outros saberes, não dá conta da complexidade do mundo. Ao definir a aprendizagem como processo cognitivo superior pelo qual o aprendiz constrói o conhecimento, desenvolvendo com autonomia sua visão de mundo e representações da realidade, o paradigma construtivista impõe mudanças que perpassam àquelas meramente exteriores.

O construtivismo aproxima o sujeito aprendente de seu meio e do outro (pares), favorecendo os movimentos de socialização. Engaja os atores do processo ensino-aprendizagem em iniciativas de reflexão acerca da prática pedagógica, seus conteúdos e as relações decorrentes ('aluno-saber', 'saber-meio' e 'aluno-meio').

O cotidiano das práticas de ensino se orienta por teorias e referenciais explicativos de natureza psicopedagógica, amálgama que thes atribuem coesão e significado, influenciando modos, modelos e expectativas. Orientando-se por essa assertiva, esse ensaio tem por objetivo lançar reflexões acerca do processo ensino-aprendizagem à luz do paradigma construtivista, elegendo-se como questão problematizante: qual a expectativa de repercussão desses pilares sobre a prática pedagógica?

De abordagem indutiva, essa pesquisa caracteriza-se como qualitativa, essencialmente bibliográfica, tendo em vista as características do campo, a produção bibliográfica acerca do tema objeto desse estudo, e a natureza da comunicação científica (TOZONI-REIS, 2009; STRAUSS, 2008)
0 artigo foi estruturado nas seguintes seções: essa introdução; referencial teórico, contendo o eixo de fundamentação segundo os objetivos propostos e considerações finais.

\section{PEDAGOGIA TRADICIONAL E O PROCESSO ENSINO-APRENDIZAGEM}

Na pedagogia tradicional, o ambiente institucional e a sala de aula, geralmente, apresentam uma organização hierarquizada, de cima para baixo, unidirecional e baseada em conhecimentos preditos (MATUI, 1995)

Os conteúdos são reproduzidos e transmitidos em 'pacotes de verdade', sem espaço para problematização ou qualquer outra forma de atuação mais proativa dos aprendentes (GRANVILLE, 2007)

Monocular e linear, as práticas baseadas nessa orientação institucionalizam 'fazeres', cristalizando estruturas e relações de poder notadamente assimétricas, reproduzindo e perenizando disfunções econômicas e sociais (VASCONCELOS; FRANÇA; SANTOS, 2013). Todavia, cumpre-nos ressaltar que o processo ensino-aprendizagem não restringe os educadores à prática de estratégias baseadas na transmissão e recepção passiva do conhecimento. As escolhas do educador o aprisionam.

A aprendizagem ocorre ininterruptamente nas fases de síncrese (percepção concreta da realidade), análise e síntese (atribuição de sentido à totalidade), o que amplia os espaços e possibilidades das práticas pedagógicas (FREIRE, 1996; LÓPEZ, 1994). O modelo tradicional, ainda presente em nossos dias, tem como característica enaltecer o papel do professor ante a dependência do discente. "Quanto mais se exercitem os educandos no arquivamento dos depósitos que lhes são feitos, tanto menos desenvolverão em si a consciência crítica de que resultaria a sua inserção no mundo como transformador dele, como sujeitos" (FREIRE, 1996).

A sociedade, historicamente, tem educado para a dependência desde a infância. 
Continuamos limitando nossas crianças ao espaço reduzido de suas carteiras, imobilizadas em seus movimentos, silenciadas em suas falas, impedidas de pensar. Reduzidas em sua criatividade e em suas possibilidades de expressão, as crianças encontram-se também limitadas em sua sociabilidade, presa à sua mente racional, impossibilitadas de experimentar novos vôos e de conquistar novos espaços. (MORAES, 1998, p. 50).

Em resposta a critica lançada ao sujeito apolítico, produto de uma educação conservadora, a sociedade vocifera as fragilidades do ensino tradicional. Todavia, alimentando-se de um paradoxo curioso, segue, reproduzindo práticas educativas, motivadas por um discurso justificador que ressalta a má qualidade da formação básica do aluno brasileiro.

As práticas pedagógicas possuem um ciclo de vida, o qual culmina, ora em sua degenerescência, ora em sua renovação. Ocorre que a defasagem de algumas práticas de ensino é percebida, mas não reconhecida em nível suficiente para catalisar mudanças comportamentais em docentes e discentes, não se vislumbrando um horizonte de ampla intervenção social.

Esse fixismo cerceante rejeita a mutabilidade e, por conseguinte, o movimento e transformação. As bases construtivistas desvelam um notório descompasso entre as demandas de formação humanísticas (integral) e a clássica pedagogia fragmentada; outrossim, revelam o anacronismo das ditas práticas 'tradicionais', usualmente tomadas como sinônimo de desatualização. $\mathrm{Na}$ mesma direção, lançam luzes às tentativas de solução dos problemas incutidos nas críticas reverberadas pelos educadores que se intitulam 'progressistas'.

O conjunto dessas reflexões engrena, na verdade, retroalimenta paradoxos, relativamente às conquistas sociais observadas nos últimos anos:

- Da demanda crescente por uma formação integral (com viés humanístico) à exposição das mazelas morais e precariedade dos relacionamentos;

- Da constatação do 'complexo' ao dicotomismo próprio da 'visão maniqueísta', expressão da inequívoca dificuldade de interpretar a realidade, filtrando os graus de intensidade das coisas;
- Das iniciativas de democratização à pastorização das práticas acadêmicas, servilismo promotor do atraso cultural da sociedade;

- Dos movimentos de inclusão social ao despreparo para (co) existir socialmente e intolerância na relação com a diversidade.

A docência tradicional, refletindo um raciocínio metafísico, baseada na mera transmissão de conhecimentos, consagra posições estáticas e verdades questionáveis, mantendo-se alheia aos movimentos sociais (numa ampla acepção). Com efeito, promovem cisões entre teoria e prática, entre o certo e o diferente, entre objeto de aprendizagem e a realidade social, entre 0 técnico e o científico, entre o profissional e o acadêmico, sem despontar situações de complementariedade.

Os adeptos desse 'fazer' maniqueísta alicerçam sua estabilidade na resistência à mudança, negando-se ao contraditório das convicções nascentes.

Inequivocamente, essa atitude fertiliza o terreno para o atraso em seus diferentes âmbitos e sentidos, capilarizando práticas ditatoriais, excludentes e intolerantes. Oferece, igualmente, guarida a perpetuação da desigualdade social e da postura antidiversidade, obstaculizando qualquer mobilidade e oxigenação das relações de poder. Revela ainda, aversão a democracia, notório alheamento às questões coletivas e naturalmente, inércia aos movimentos e pressões político-sociais.

Os adeptos dessa visão advogam a neutralidade política, quando na verdade, a omissão também constitui uma escolha, em geral desfavorável a mudança e a reorganização das posições sociais. Significa afirmar que essa pedagogia instrumental dos modelos definitivos apresenta alguma nocividade social, servindo de esteio para a dominação e exploração do homem pelo homem.

Matui (1995, p. 9) destaca que, "Infelizmente, a grande maioria das práticas pedagógicas tem uma visão fixista e maniqueísta do mundo". Promover divisões, em lugar de 'classificações transitórias', enseja uma segregação que perpassa os muros institucionais, o que remete a uma reflexão pertinente acerca da 'mensagem subliminar' (atitudinal, comportamental e moral) comunicada aos discentes nas instituições de ensino. Essa fragmentação patrocina um re- 
ducionismo de campo que afasta o entendimento do todo, sem dar conta, portanto, da complexidade do mundo e suas realidades multifacetadas.

Objeto de debates inadiáveis, a interdisciplinaridade apresenta-se como demanda emergente ante a insuficiência dos clássicos 'saberes disciplinarizados' para compreensão da realidade e sua diversidade integradora.

A hiperespecialização ainda presente no ensino produz ilhas epistemológicas eivadas de explicações parciais, naturalmente incompletas, muitas vezes acríticas e alienantes. Os saberes se desenvolvem numa realidade complexa (ética, histórica, social e culturalmente constituída), quadro que reclama uma renovação multiparadigmática das práticas pedagógicas.

\section{REPERCUSSÃO DO CONSTRUTIVISMO DIALÉTICO PARA A PRÁTICA ENSINO-APRENDIZAGEM}

Definir o construtivismo é desafiante porque compreende e acomoda diferentes leituras. Os construtivistas cunharam seus entendimentos em cenários, cultura e épocas distintas, alicerçados em estudos sistematizados, ou meramente, em impressões, experiências e pontos de vista. A convergência da análise desse mosaico de entendimentos é que o sentido filosófico do 'fazer' construtivista descontrói paradigmas enraizados na sociedade, colocando em reflexão a qualidade das práticas pedagógicas sob o prisma da autonomia, dignidade e autodeterminação do educando.

De fato, "[...] os construtivistas recusam a concepção de uma natureza humana universal, essencial e estática, herança da metafísica tradicional, já que o ser humano se faz e se refaz pela interação social e por sua ação sobre o mundo" (ARANHA, 2006, p. 275).

0 referencial construtivista, opondo-se frontalmente ao objetivismo, desafia e desacomoda crenças, desinstalando comandos prescritivos, resgatando o sentido primordial da educação: organizar a relação do homem com o ambiente, a fim de proporcionar condições de desenvolvimento e promovê-lo culturalmente. Nesse entendimento, promover o homem implica reconhecê-lo como sujeito histórico, dotado de autonomia no comando do processo de elaboração do conhecimento, ressaltando sua capacidade de problematização e intervenção. (SAVIANI, 2007) "O construtivismo realça justamente a capacidade adaptativa da inteligência e da afetividade, dando condições para que o processo de amadurecimento não seja ilusório, o que acontece quando resulta de pressões externas sem a 'gestação' por parte do sujeito" (ARANHA, 2006, p. 276).

O construtivismo dialético ou híbrido, inspirado nos estudos de Piaget e Vygotsky, reconhece as faces intra e interpsicológica do fenômeno da aprendizagem, definindo-a como processo de autoria empreendido pelo sujeito aprendiz.

Esse ponto de vista refuta, portanto, a ideia do conhecimento como um produto meramente demonstrável ou imposto. Nessa direção, pressupõe o desenvolvimento dos objetos de aprendizagem, sem ignorar a importância da realidade social e suas interações como fonte de insights. Implica afirmar que o fenômeno da aprendizagem compreende desde a consulta e ressignificação de esquemas de interpretação pré-existentes à elaboração de esquemas novos (processo 'inter-intra') (ACKERMANN, 2001; SERRANO GONZALEZ-TEJERO; PONS PARRA, 2011; STROMMEN; LINCOLN, 1992)

0 professor educa pessoas, voltando-se necessariamente para o mundo, o humano, o social e o político. Educar é um ato político, onde a superação do senso comum se opera no afrontamento, na análise crítica e intervenção social. Nesse contexto de ressignificação, a prática docente não é neutra.

Naturalmente, a ênfase Vygotskyana nas origens sociais dos processos psicológicos superiores, bem como a primazia dos processos em detrimento dos produtos, característica de seu método de análise, refletem as raízes marxistas de sua proposta. (MOREIRA, 1999, p. 110).

A aprendizagem não é um fenômeno essencialmente intrapsicológico, endógeno ou hermético, relativamente às influências externas e condicionantes dos processos sociais. Os conflitos, a negociação, as demandas de cooperação e a própria comunicação são 
motivos à reconstrução ou reelaboração de esquemas prévios presentes na estrutura cognitiva do indivíduo. 0 ambiente é fecundo em estímulos promotores de reflexão e elaboração do conhecimento. A aprendizagem se enquadra, nesse contexto, como reação contínua (volitiva ou não) a esses estímulos (GALLEGO BADILLO; PÉREZ MIRANDA, 1993; PERKINS, 1992; STROMMEN; LINCOLN, 1992)

O pensamento construtivista não trata o conhecimento como absoluto porque reconhece os movimentos de continuada transformação. 0 mundo é interpretado pelo sujeito cognoscente sob um ponto de vista histórico-sociocultural, o que pressupõe redesenhos peculiares da realidade investigada.

"O conhecimento se origina na interação do sujeito com a realidade ou desta com o sujeito, seja ela a realidade física, social ou cultural" (MORAES, 2000, p. 116). Ao professor cabe, tão somente, compartilhar experiências, cooperar, mediar, orientar e facilitar a organização de conteúdos à luz do conhecimento já desenvolvido (sedimentado) (BELTRÁN, 1993; BERGER; LUCKMANN, 2001; GARCÍA; CUBERO, 2000).

A insubmissão do aluno, sua insatisfação e curiosidade o impulsionam em direção à força criadora de aprender, tornando sua aprendizagem mais rica. Nesse processo, é indispensável que docentes e alunos se percebam como seres inacabados, inconclusos, em constante formação. (RICARDO; VILARINHO, 2006, p. 108).

Apesar da força das argumentações propostas, o modelo tradicional de ensino concentra as responsabilidades do processo de aprendizagem no professor, reduzindo seu papel a um mero reprodutor de conhecimentos e fornecedor de 'soluções' ou 'gabaritos' para as diferentes situações do cotidiano (professor como expert, autoridade) (BELTRÁN, 1993; BERGER; LUCKMANN, 2001; LÓPEZ, 1994; SERRANO GONZALEZ-TEJERO; PONS PARRA, 2011).

O construtivismo valoriza, então, o aluno como sujeito ativo no processo ensino-aprendizagem, contemplando seus motivos, inquietações, demandas, intenções, afetividade, expectativas e relações (DICK, 1992). Depreende-se então que "O sujeito para o construtivismo é proativo, é foco de atividade do universo e não um aglomerado de células que recebe passivamente estímulos do ambiente, sendo movidas por estes" (CASTAÑON, 2005, p. 38).

Com esse desenho progressista, o construtivismo

[...] inovou no sentido de respeitar as ideias do aprendiz, de estar compromissado com um ensino significativo, capitalizando e utilizando o que o estudante já sabe, valorizando a aprendizagem em grupo, a aprendizagem cooperativa, por perguntas ou investigação, identificando um importante papel pedagógico para a história e a filosofia da ciência, etc. (LABURÚ; CARVALHO; BATISTA, 2001, p. 153).

Essa valorização repousa na crença de que a existência humana não tem um fim determinado, sendo definida pelo livre arbítrio do indivíduo inacabado e mutável (concepção existencialista da vida): 'suas escolhas, sua responsabilidade e consequências' (MATUI, 1995).

Nessa direção, consolida entendimento de que “[...] o conhecimento não é o resultado de uma mera cópia da realidade pré-existente, mas um processo dinâmico e interativo através do qual a informação externa é interpretada e reinterpretada pela mente" (SERRANO GONZALEZ-TEJERO; PONS PARRA, 2011). O pensamento construtivista reduz a assimetria na relação docente-discente no desempenho de seus papéis no processo ensino-aprendizagem; posição coerente, pois: "A Educação, enquanto fenômeno, apresenta-se como uma comunicação entre pessoas livres em graus diferentes de maturação humana, numa situação histórica determinada" (SAVIANI, 2007, p. 59).

Uma das críticas e restrição lançadas ao construtivismo, quando aplicado à realidade brasileira, diz respeito às fragilidades pedagógicas que se avolumam, sem solução, ao longo do ciclo de formação escolar do indivíduo (problema rotulado como 'falta de base'). Entretanto, a prática construtivista não anula a responsabilidade e carga de competência do docente; igualmente, não elimina a clássica troca de conhecimentos (partindo do professor em direção ao aluno). 0 pensamento construtivista, apenas, não desprestigia a experiência, as impressões de mundo e fatores condicio- 
nantes da realidade do aluno (saberes locais, aspectos culturais, regionais, históricos e geográficos). Afinal,

[...] o sujeito é constituído por diferentes aspectos, como: aprendizagens anteriores, ou seja, conhecimentos já interiorizados, hábitos que possui, motivações presentes, funcionamento cognitivo, curiosidades pelo mundo que o cerca, experiências culturais e sociais em que o sujeito está envolvido. (BACKES; FOCESI, 2010, p. 26).

Destaque-se que “[...] os conteúdos reúnem dimensões conceituais, ideológicas, políticas, culturais, educacionais que devem ser explicitadas e apreendidas no processo ensino-aprendizagem" (GASPARIN, 2007, p. 2).

0 professor, nesse contexto, maneja didaticamente esses elementos, visando mediar e facilitar a compreensão acerca do objeto de aprendizagem, lente que enfatiza a formação cidadã e não meramente a produção de um perfil de mercado, próprio da universidade 'operacional'.

\section{NUANCES CONSTRUTIVISTAS}

As configurações possíveis dessa realidade produzem verdadeiras nuances construtivistas, as quais, por influência, moldam o pensamento e papéis dos atores no processo ensino-aprendizagem. A própria expressão abriga diferentes visões, com peculiaridades e traços diferenciadores (DUFFY; CUNNINGHAM, 1996; FOSNOT, 2013).

Essa diversidade de olhares orienta-se por conceitos, inclinações políticas, impressões da realidade e teorias de aprendizagem, ensejando territórios de abordagem com escopos e ênfases distintos. Assim, tratar sobre o tema em tela iniludivelmente convida-nos a um debate eivado de posições extremadas e idealizadas.

Destarte, em razão da notória complexidade, o construtivismo não se define como método ou técnica, mas como amplo referencial teórico dotado de diretrizes pedagógico-filosóficas. Essa característica cria tensões interessantes no diálogo em torno dos elementos componentes desse eixo diretivo (pedagógico-filosófico).
As releituras desvelam desde posições convergentes, posicionadas nas proximidades do eixo, àquelas divergentes em diferentes níveis (posicionadas na periferia desse eixo). As versões ora fortalecem as clássicas definições, ora promovem a ressignificação do referencial epistemológico (CARRETERO, 2002; GRANDESSO, 2000; NOVAK, 1988; SALVADOR, 1990; URIBE, 1998; URIBE, 2003). "O contraste entre a realidade e a orientação construtivista mostra como sua implantação requer novos enfoques, para que o ensino ultrapasse a padronização e atinja a flexibilidade necessária à elaboração do conhecimento" (MICOTTI, 1994, p. 7).

A banalização de propostas, empreendidas no ânimo das idealizações, alimentam a resistência a essa pensamento (BARRETO TOVAR et al., 2006). 0 construtivismo coloca em relevo a dimensão política do trabalho do professor e participação do aluno; concomitantemente, convida-os a refletir politicamente acerca da ampla realidade social e aquela estritamente educativa, admitindo que o conhecimento “[...] como fato histórico e social supõe sempre continuidades, rupturas, reelaborações, reincorporações, permanências e avanços" (GASPARIN, 2007, p. 4).

Em tempo, provoca uma interlocução proativa e mobilizadora com o mundo, incitando à ação direcionada a transformação (para além da denúncia e anúncio velado das fragilidades do ensino no formato tradicional), e por meio dela, à libertação de paradigmas inócuos, desatualizados e do nocivo imobilismo social (FREIRE, 1996; FREITAS, 2004).

Por esse prisma, a indignação constitui, tão somente, reflexo do despertamento para as implicações daquela realidade problematizada, encadeadora da criticidade. (FREITAS, 2004). A centralidade da prática acadêmica construtivista é a consciência 'do quê', 'por quê' e 'para quê' ou 'quem' se faz, e ainda, da trajetória profissional de cada agente do processo ensino-aprendizagem.

Nessa direção, promove uma ruptura com a dependência patrocinada pelas atividades prescritivas, acríticas, impregnadas de posições dogmáticas, descoladas do contexto social, portanto, vazias de sentido político. A liberdade tão anunciada nos discursos dos autores refere-se a conquista da autonomia reflexiva e prontidão à intervenção social. 


\section{CONSIDERAÇ̄̃ES FINAIS}

Na medida em que se baseia na horizontalização de saberes e prestígio do repertório cognitivo do aprendente, o construtivismo reconfigura papéis e redefine as posições dos atores no processo ensino-aprendizagem.

Inobstante valorize as liberdades, promovendo uma democracia cognitiva, o construtivismo não desresponsabiliza o professor ou as instituições de ensino. Os papéis não são extintos, apenas revistos e ressinificados.

Os níveis de comando do professor relativamente ao processo ensino-aprendizagem permanecem, mas em dosagens que não produzam dependência excessiva, comprometam a autodeterminação do aprendente ou violam sua dignidade.

O 'pensamento construtivista' não apassiva o aprendiz, tratando-o como um depósito de informações ou arquivo de predisposições inatas. Ao contrário, promove a importância do aproveitamento de sua expertise e conhecimentos prévios, essencial à ressignificação e contextualização dos conteúdos. Igualmente, não supervaloriza o professor, desafiando-o à repensar sua prática pedagógica e estratégias, de modo a facilitar a aprendizagem.

0 anacronismo de 'fazeres' mecânicos, acríticos, anistóricos, essencialmente técnicos, não comprometidos com as demandas da aprendizagem, grita por movimentos de superação e renovação.

O construtivismo, contrapondo-se ao movimento reducionista da realidade complexa, à disciplinaridade de conhecimentos conectados, a visão fixista e ao reprodutivismo socialmente imobilizante, valoriza o sujeito, a prática cultural dialógica, a interação e a densidade plural dos saberes, ampliando e propondo novas trilhas de aprendizagem.

A concepção construtivista tem um escopo mais amplo, sobrepondo-se àquela de natureza meramente instrucional, por essa razão não prediz ou exclusivisa trajetos, roteiros, métodos ou técnicas. A trivialização do construtivismo está geralmente associada a entraves de natureza prática, ou meramente de ruídos em sua interpretação. Apesar dessas dos argumentos apresentados, amplamente tratados na literatura que desenvolve a matéria, o debate sobre a repercussão do ideário construtivista segue irresoluto. Os pontos de vista, entretanto, convergem em direção ao reconhecimento do valor pedagógico do referencial explicativo, inobstante se reconheça restrições e desafios de aplicação.

\section{REFERÊNCIAS}

ACKERMANN, E. Piaget's constructivism, papert's constructionism: what's the difference. Future

Oflearning Group Publication, v.5, n.3, p.438, 2001.

ARANHA, Maria Lúcia de Arruda. História da educação e da pedagogia. São Paulo: Moderna, 2006

BACKES, D.I.M.; FOCESI, L.V. Um espaço de vivência e reflexão do saber psicopedagógico. In: KOPZINSKI, S.D. (Org.). Percursos psicopedagógicos: entre o saber e o fazer. Novo Hamburgo: Universidade Feevale, 2010. p.25-37.

BARRETO TOVAR, C.H. et al. Límites del constructivismo pedagógico. Educación y

Educadores, v.9, n.1, p.11-31, 2006.

\section{BELTRÁN, J. Procesos, estrategias y técnicas de} aprendizaje. Madrid: Síntesis, 1993.

BERGER, P.L.; LUCKMANN, T. La construcción social

de La realidad. Madrid: Amorrortu, 2001.

CARRETERO, M. Construtivismo e educação. 2.ed. Porto Alegre: Artmed, 2002.

CASTAÑON, G.A. Construtivismo e ciências humanas. Ciências \& Cognição, v.5, p.36-49, 2005.

DICK, W. An instructional designer's view of constructivism. In: DUFFY, T.M.; JONASSEN, D.H.

(Ed.). Constructivism and the technology of 
instruction: a conversation. New Jersey: Erlbaum, 1992. p.91-98.

DUFFY, T.; CUNNINGHAM, D. Constructivism: implications for the design and delivery of instruction. In: JONASSEN, D.H. (Ed.). Handbook of research for educational communications and technology. New York: Simon and Schuster, 1996. p.170-198.

FOSNOT, C.T. (Ed.). Constructivism: theory, perspectives, and practice. New York: Teachers College Press, 2013.

FREIRE, P. Pedagogia da autonomia: saberes necessários à prática educativa. São Paulo: Paz e Terra, 1996. (Coleção Leitura).

FREITAS, A.L.S. Pedagogia da conscientização: um legado de Paulo Freire à formação de professores. Porto Alegre: EDIPUCRS, 2004.

GADOTTI, M. A escola e o professor: Paulo Freire e a paixão de ensinar. São Paulo: Publisher Brasil, 2007.

GALLEGO BADILLO, R.; PÉREZ MIRANDA, R. Discurso sobre el constructivismo. Bogotá: Rojas Eberhard,1993. p.9-81.

GARCÍA, J.E.; CUBERO, R. Constructivismo y formación inicial del profesorado. Investigación em La Escuela, v.42, p.55-66, 2000.

GASPARIN, J.L. Uma didática para a pedagogia históricocrítica. Campinas, SP: Autores Associados, 2007.

GRANDESSO, M. Sobre a reconstrução do significado: uma análise epistemológica e hermenêutica da prática clínica. São Paulo: Casa do Psicólogo, 2000.

GRAVILLE, M.A. Teorias e práticas na formação de professores. Campinas, SP: Papirus, 2007.
LABURÚ, C.E.; CARVALHO, M.A.; BATISTA, I.L. Controvérsias construtivistas. Caderno Brasileiro de Ensino de Física, v.18, n.2, p.152-181, ago. 2001.

LAKOMY, A. M. Teorias cognitivas da aprendizagem. 2.ed. rev. atual. Curitiba: Ibpex, 2008.

LÓPEZ, M.J.R. El hombre de la calle, el científico y el alumno: ¿un solo constructivismo o tres? Investigación en la Escuela, n.23, p.7-16, 1994. MATUI, J. Construtivismo: teoria construtivista sócio-histórica aplicada ao ensino. São Paulo: Moderna, 1995.

MICOTTI, M.C.O. O construtivismo e a prática da alfabetização. Revista Educação: teoria e prática, v.2, n.3, p.6-11, dez. 1994.

MORAES, M.C. 0 paradigma educacional emergente. Campinas: Papirus, 1998.

MORAES, R. É possível ser construtivista no ensino de Ciências? In: MORAES, R. (Org.). Construtivismo e ensino de Ciências: reflexões epistemológicas e metodológicas. Porto Alegre: EDIPUCRS, 2000. p.103-129.

MORAN, J.M. Contribuições para uma pedagogia da educação on-line. In. SILVA, M. Educação online: teorias, práticas, legislação, formação corporativa. São Paulo: Loyola, 2011. p.41-52.

MOREIRA, M.A. Teorias de aprendizagem. São Paulo: E.P.U., 1999.

NOVAK, J.D. Constructivismo humano: un consenso emergente. Enseñanza de las Ciencias: Revista de Investigación y Experiencias Didácticas, v.6, n.3, p.213-223, 1988.

PERKINS, D.N. Technology meets constructivism: do they make a marriage. In: DUFFY, T.M.; JONASSEN, D.H. (Ed.). Constructivism and the technology of 
instruction: a conversation. Hillsdale, $\mathrm{NJ}$ : Lawrence Erlbaum Associates, 1992. p.45-55.

REMY, H.D.Z. El constructivismo en losprocesos de enseñanza-aprendizaje en el siglo XXI. Barcelona: Plaza Y Valdes, 2004.

SALVADOR, C.C. Constructivismo y educación: la concepción constructivista de La enseñanza y del aprendizaje. In: SALVADOR, C.C.; PALACIOS, J.; MARCHESI

ULLASTRES, A. (Comp.). Desarrollo psicológico y educación: 2. Psicologia de la educación escolar. Madrid: Alianza, 1990. p.157-188.

SAVIANI, D. Educação: do senso comum à consciência filosófica. Campinas, SP: Autores Associados, 2007.

SERRANO GONZALEZ-TEJERO, J.M.; PONS PARRA, R.M. El constructivismo hoy: enfoques constructiv istaseneducación. REDIE. Revista Electrónica de Investigación Educativa, Ensenada, v.13, n.1, jan. 2011.

STRAUSS, A.; CORBIN, J. Pesquisa qualitativa: técnicas e procedimentos para o desenvolvimento de teoria fundamentada. Porto Alegre: Artmed, 2008.
STROMMEN, E.F.; LINCOLN, B. Constructivism, technology, and the future of classroom learning. Ed ucationandUrbanSociety, v.24, n.4, p.466-476, 1992.

TOZONI-REIS, M.F.C. Metodologia da pesquisa.

Curitiba: IESDE Brasil S/A, 2009.

URIBE, C.E.V. (Ed.) Constructivismo en el aula:¿

ilusiones o realidades? Bogotá: Pontificia

Universidad Javeriana, 1998.

URIBE, C.E.V. (Ed.). Posmodernidad, ciencias y educación. Bogotá: Pontificia Universidad Javeriana, 2003.

VASCONCELOS, Y.L.; FRANÇA, S.M.; SANTOS, F.M. Estratégias de ensino aplicáveis na educação a distância. UNOPAR Científica Ciências Humanas e Educação, Londrina, v.14, n.3, p.183-188, out. 2013.

VYGOTSKY, L. S. A formação social da mente. São Paulo: Martins Fontes, 1984.

ZABALA, A. A prática educativa: como ensinar. Porto Alegre: Artmed, 1998.
Recebido em: 01 de maio de 2016

Avaliado em: 28 de junho de 2016

Aceito em: 05 de março de 2017

\footnotetext{
1 Doutorado em Direitos Humanos - PPGDH/UFPE; Docente na Universidade Federal Rural de Pernambuco, no curso de Administração e do Programa de Pós-Graduação em desenvolvimento rural e do PPGDH - Programa de pós-graduação em Direitos Humanos - UFPE; Líder o grupo de pesquisa GEPDH - Grupo de Estudos e Pesquisas em Direitos Humanos. E-mail: yumaravasconcelos@gmail.com

2 Graduado e Bacharel em Biblioteconomia pela Universidade Federal de Pernambuco (1985) e em Ciências Sociais pela Universidade Católica de Pernambuco (1975). E-mail: suely.sulamanzi@gmail.com
} 